\title{
Persistent Empiric COPD Diagnosis and Treatment After Pulmonary Function Test Showed No Obstruction
}

\author{
Spyridon Fortis MD, Edward O Corazalla MSc RPFT, David R Jacobs Jr PhD, and \\ Hyun J Kim MD
}

\begin{abstract}
BACKGROUND: Health-care providers often diagnose and empirically treat COPD without a confirmative pulmonary function test (PFT) or even despite a PFT that is not diagnostic of obstructive lung disease. We hypothesized that a portion of patients continue to carry a persistent empiric COPD diagnosis and receive treatment with bronchodilators and inhaled steroids after a PFT shows no obstruction. METHODS: We retrospectively reviewed single PFT sessions with both spirometry and plethysmography in 1,805 subjects. We included subjects who had a normal PFT or a restrictive ventilatory defect. Persistent empiric COPD diagnosis and treatment were defined when subjects with normal PFTs or a restrictive ventilatory defect continued to carry a health-care provider COPD diagnosis or receive treatment with bronchodilators and/or inhaled glucocorticoids, respectively, after a PFT showed no obstruction. RESULTS: One quarter of subjects with FEV $1 / F V C \geq$ lower limit of the normal range had nonspecific PFT abnormalities. We included 473 subjects with normal PFTs and 382 with a restrictive ventilatory defect $(n=855)$. Persistent empiric COPD diagnosis (60 of $855,7 \%$ prevalence) was associated with current (odds ratio $[O R]=44.7, P<.001)$ and former smoking $(O R=17.3, P<.001)$ and older age $(O R=1.03 / y$, $P=.005)$. Persistent empiric treatment $(208$ of $855,24 \%)$ was associated with empiric COPD diagnosis $(O R=24.6, P<.001)$, female sex $(O R=1.75, P=.002)$, current $(O R=2.04, P=0.040)$ and former smoking $(\mathrm{OR}=1.53, P=0.029)$, interstitial lung disease $(\mathrm{OR}=2.09, P=.001)$, other respiratory diagnosis $(\mathrm{OR}=3.17, P<.001)$, and obstructive sleep apnea $(\mathrm{OR}=1.79, P=.006)$. CONCLUSIONS: Persistent empiric COPD diagnosis was 7\%, but persistent empiric treatment was common. Key words: diagnosis; diagnostic errors; COPD; plethysmography; pulmonary function tests; spirometry. [Respir Care 2016;61(9):1192-1200. (C) 2016 Daedalus Enterprises]
\end{abstract}

\section{Introduction}

Health-care providers often diagnose and empirically treat COPD without confirmation by pulmonary function tests (PFTs). ${ }^{1-4}$ A recent study in the Veterans Affairs

\footnotetext{
At the time of this study, Dr Fortis was affiliated with the Division of Pulmonary and Critical Care, Department of Medicine, University of Minnesota, Minneapolis, Minnesota. Mr Corazalla and Dr Kim are affiliated with the Pulmonary Function Test Laboratory, University of Minnesota Medical Center, Minneapolis, Minnesota. Dr Kim is also affiliated with the Division of Pulmonary and Critical Care, Department of Medicine, University of Minnesota, Minneapolis, Minnesota. Dr Jacobs is affiliated with the Division of Epidemiology and Community Health, School of Public Health, University of Minnesota, Minneapolis, Minnesota.
}

The authors have disclosed no conflicts of interest. health-care system showed that $45 \%$ of the subjects who carried an empiric COPD diagnosis and $38 \%$ of those who received empiric treatment before their PFTs had no obstruction, defined as $\mathrm{FEV}_{1} / \mathrm{FVC} \geq$ lower limit of normal. ${ }^{2}$ Even after a PFT shows no obstruction, physicians often continue to empirically treat individuals with medications like bronchodilators. ${ }^{3,5}$ Persistent empiric COPD diagnosis and treatment after the PFT has shown no obstruction have not been well described. ${ }^{3,5}$

\footnotetext{
Correspondence: Spyridon Fortis MD, Internal Medicine, University of Iowa Health Center, 200 Hawkins Drive, C33 GH, Iowa City, IA 52242. E-mail: spyridon-fortis@uiowa.edu.
}

DOI: $10.4187 /$ respcare. 04647 
Previous studies may have overestimated empiric COPD and treatment because they used only spirometric criteria, although $\mathrm{FEV}_{1} / \mathrm{FVC} \geq$ lower limit of normal alone is not sufficient to rule out COPD. Often in COPD, $\mathrm{FEV}_{1}$ may be reduced concomitantly with $\mathrm{FVC}$, and the ratio may appear normal. ${ }^{6}$ Lung volumes are necessary to distinguish between a restriction ventilatory defect and a nonspecific PFT pattern. ${ }^{6,7}$

Moreover, health-care providers often prescribe bronchodilators or inhaled glucocorticoids even in patients with no COPD or other respiratory diseases because they are relatively safe medications and may offer limited symptom relief. Therefore, empiric treatment must be examined separately from empiric COPD diagnosis.

We hypothesized that a portion of patients continue to carry an empiric COPD diagnosis and receive treatment with bronchodilators or inhaled glucocorticoids after a PFT that includes both spirometry and lung volume measurements shows no obstruction. Our objectives were (1) to estimate the extent of persistent empiric COPD diagnosis and empiric treatment with bronchodilators and/or inhaled glucocorticoids and (2) to identify factors associated with them in individuals who carried such a diagnosis and treatment long enough after the PFTs that included both spirometry and lung volume measurements were not diagnostic of obstructive lung disease according to American Thoracic Society-European Respiratory Society (ATSERS) guidelines. ${ }^{6}$ We reviewed subjects whose PFTs (single session) included both spirometry and plethysmography. We included all patients except for those with $\mathrm{FEV}_{1} / \mathrm{FVC}<$ lower limit of normal or nonspecific patterns. We will only include subjects with: (1) normal PFTs and (2) a restrictive ventilatory defect. We identified characteristics associated with persistent empiric COPD diagnosis and persistent empiric treatment with bronchodilators and/or inhaled glucocorticoids despite a PFT inconsistent with obstructive lung disease.

\section{Methods}

The study protocol was reviewed and approved (exempt status, study number: 1501E60401) by the University of Minnesota institutional review board, in accordance with the Code of Federal Regulations, 45 CFR 46.101(b).

\section{Data Collection}

To construct our study data set, we retrieved data from 1,805 patients $\geq 18 \mathrm{y}$ old. All PFTs included both spirometry and plethysmography and were performed between January 1, 2013, and August 15, 2013 in the Fairview health system in Minnesota, as described previously. ${ }^{8}$ If there were multiple PFT sessions for a single individual, only the first was included. All PFTs were performed ac-

\section{QUICK LOOK}

\section{Current knowledge}

Health-care providers often diagnose and empirically treat COPD without a confirmative pulmonary function test (PFT) or even despite a PFT that is not diagnostic of obstructive lung disease. Previous studies used only spirometric criteria for diagnosis, and they did not examine whether the patients carried the COPD diagnosis and continued treatment after the PFT showed no obstruction.

\section{What this paper contributes to our knowledge}

One quarter of the subjects with normal $\mathrm{FEV}_{1} / \mathrm{FVC}$ had nonspecific PFT abnormalities. Seven percent of the subjects continued to carry an empiric COPD diagnosis after PFT showed no obstruction. Persistent empiric COPD diagnosis was more common among the elderly and smokers. Persistent empiric treatment with bronchodilators and/or inhaled glucocorticoids occurred in $24 \%$ of the subjects and was associated with female sex, smoking, empiric COPD diagnosis, interstitial lung disease, other respiratory diagnosis, and OSA.

cording to ATS-ERS guidelines and met the ATS-ERS standards for acceptability and repeatability.9-11

To provide a more accurate estimate of empiric COPD diagnosis and treatment with bronchodilators and/or inhaled glucocorticoids, apart from patients with $\mathrm{FEV}_{1} / \mathrm{FVC}<$ lower limit of normal, we also did not include patients who had nonspecific PFT patterns, defined as $\mathrm{FEV}_{1}$ or $\mathrm{FVC}<$ lower limit of normal, $\mathrm{FEV}_{1} / \mathrm{FVC} \geq$ lower limit of normal, and TLC $\geq$ lower limit of normal, 7,12 which could potentially be part of the obstructive spectrum.

In the present project, out of all 1,805 patients with PFTs, we included only subjects with normal PFTs or restrictive ventilatory defect. Those individuals with normal PFTs had $\mathrm{FEV}_{1} \geq$ lower limit of normal, FVC $\geq$ lower limit of normal, and $\mathrm{FEV}_{1} / \mathrm{FVC} \geq$ lower limit of normal based on the predicted values derived from the National Health and Nutrition Examination Survey III ${ }^{13}$ and no air trapping and/or hyperinflation by measurement of lung volumes. Air trapping and/or hyperinflation was defined as total lung capacity, residual volume, or residual volume/total lung capacity ratio above the upper limit of normal. ${ }^{6,14}$ Subjects with a restrictive ventilatory defect had $\mathrm{FEV}_{1} / \mathrm{FVC} \geq$ lower limit of normal, $\mathrm{FVC}<$ lower limit of normal, ${ }^{13}$ and total lung capacity $<$ lower limit of normal ${ }^{14}$ according to ATS-ERS guidelines. ${ }^{6}$ PFTs were performed using Medical Graphics Diagnostics Corporation equipment and BreezeSuite 7.1 software (MGC Diagnostics, St Paul, MN). We extracted the following 
data from each subject's PFT record: age, race, height, sex, and weight.

One of the authors reviewed the electronic medical record from February 2014 to February 2015 (6-25 months after the PFT) and extracted the respiratory clinical diagnosis. First, we reviewed the past medical history and problem list, which are distinct data in the electronic medical record. Second, we reviewed health-care provider notes (pulmonologist's or primary care physician's note if there were no visit to a pulmonologist) to confirm the respiratory diagnosis starting from the most recent encounter. All of the providers have the exact same information/access to the PFT results. We extracted the following respiratory clinical diagnoses: (1) COPD; (2) interstitial lung disease; (3) other respiratory diagnosis, including primary pulmonary hypertension, pulmonary embolism, myopathy, dyspnea, and cough; and (4) no respiratory diagnosis. If the subject carried both the diagnosis of asthma and COPD, we recorded it as COPD.

We excluded patients with asthma, alveolar proteinosis, bronchiectasis, interstitial pneumonia with an obstructive component like follicular bronchiolitis, desquamative interstitial pneumonia and respiratory bronchiolitis, lung cancer, lung transplant, and sarcoidosis. We extracted smoking status and treatment with short-acting $\beta$ agonists, inhaled/nebulized glucocorticoids long-acting $\beta$ agonists, and anticholinergics. We also extracted comorbidities from the past medical history and problem list, which are distinct data in the electronic medical record: coronary artery disease, heart failure, chronic kidney disease, diabetes mellitus, hypertension, and obstructive sleep apnea (OSA).

Physicians often give a working diagnosis and even prescribe short-term temporary treatment with bronchodilators and/or inhaled glucocorticoids while awaiting confirmation by the PFTs. To capture persistent empiric COPD diagnosis and treatment, we reviewed the electronic medical records of subjects with empiric COPD diagnosis and/or empiric treatment for a second time in March and April 2015 (19-26 months after the PFTs), which is a long enough interval to ensure that physicians have reviewed the PFTs. If the physician diagnosis or treatment changed post-PFT, we recorded only the last diagnosis. We excluded patients who did not have pulmonary or primary care clinic encounters after their PFTs.

\section{Definitions and Outcomes}

We defined persistent empiric COPD diagnosis as when a subject continued to carry the COPD diagnosis by the health-care provider after a normal PFT or a PFT with a restrictive ventilatory defect. Similarly, we defined persistent empiric treatment with bronchodilators and/or inhaled glucocorticoids as when a subject continued to receive treatment, including short-acting $\beta$ agonists, inhaled/nebulized glu- cocorticoids long-acting $\beta$ agonists, and anticholinergics, after a PFT that indicated no obstruction.

We stratified subjects with persistent empirical treatment by respiratory diagnosis and the presence of a restrictive ventilatory defect to identify patterns that correlate for empirical treatment. We performed multivariable logistic regressions to identify factors associated with (1) persistent empiric COPD diagnosis in the total sample and regardless of smoking status and (2) persistent empiric treatment in the total sample and regardless of the respiratory diagnosis.

\section{Statistical Analysis}

We performed a univariate analysis for variables associated with persistent empiric COPD diagnosis. Variables univariately associated with persistent empiric COPD diagnosis with a $P$ value of $<.1$ were entered into the multivariable logistic regression model. We also performed a univariate analysis for variables associated with persistent empiric treatment. Variables associated with empiric persistent treatment with a univariate $P$ value of $<.1$ were entered into the corresponding multivariable logistic regression model. In multivariable logistic regression models, variables were selected using a backward stepwise process; a $P$ value of $>.1$ was used to delete variables in subsequent steps. All analyses were carried out using Epi Info 7 statistical software.

\section{Results}

Of 1,805 patients we did not include in our analysis 421 with $\mathrm{FEV}_{1} / \mathrm{FVC}<$ lower limit of normal with obstruction and 354 with $\mathrm{FEV}_{1} / \mathrm{FVC} \geq$ lower limit of normal with nonspecific PFT abnormalities: (1) FVC $<$ lower limit of normal with total lung capacity $<$ lower limit of normal $(n=234)$, (2) hyperinflation and/or air trapping with normal FEV 1 and FVC $(n=88)$, and (3) $\mathrm{FEV}_{1}<$ lower limit of normal with normal $\mathrm{FEV}_{1} / \mathrm{FVC}$ and $\mathrm{FVC}(n=32)$ (Fig. 1). One hundred seventy-five met the exclusion criteria (Fig. 2). Of the remaining 855 who were included in the analysis, 473 (55.3\%) had normal PFTs, and 382 (44.7\%) had a restrictive ventilatory defect.

In the first chart review, 79 subjects $(9.2 \%)$ had an empiric COPD diagnosis, and 227 (26.5\%) received empiric treatment. In the second chart review, physicians retracted the empiric COPD diagnosis in 19 subjects ("overdiagnosed"), and they stopped the empiric treatment in 8 of these 19 subjects. Eleven more subjects who were receiving empiric treatment ("overtreated") stopped treatment in the second chart review.

After the second electronic medical record review, 60 subjects $(7 \%)$ continued to carry an empiric COPD diagnosis, and 208 (24.3\%) continued to receive empiric treat- 


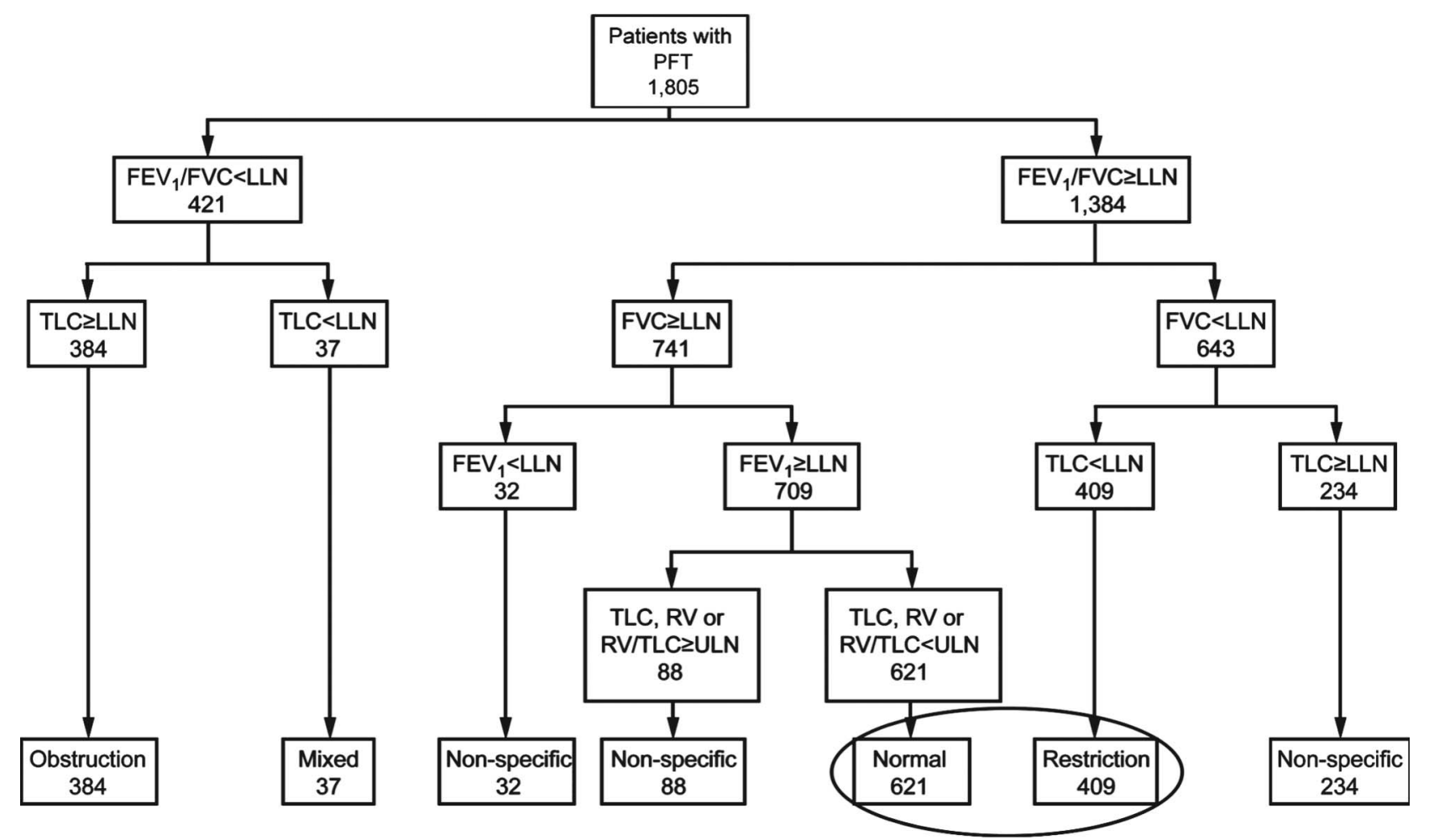

Fig. 1. Schematic diagram of diagnosis according to pulmonary function tests. The circle highlights the subjects included in the study. PFTs = pulmonary function tests, RV = residual volume, TLC = total lung capacity, LLN = lower limit of normal, ULN $=$ upper limit of normal.

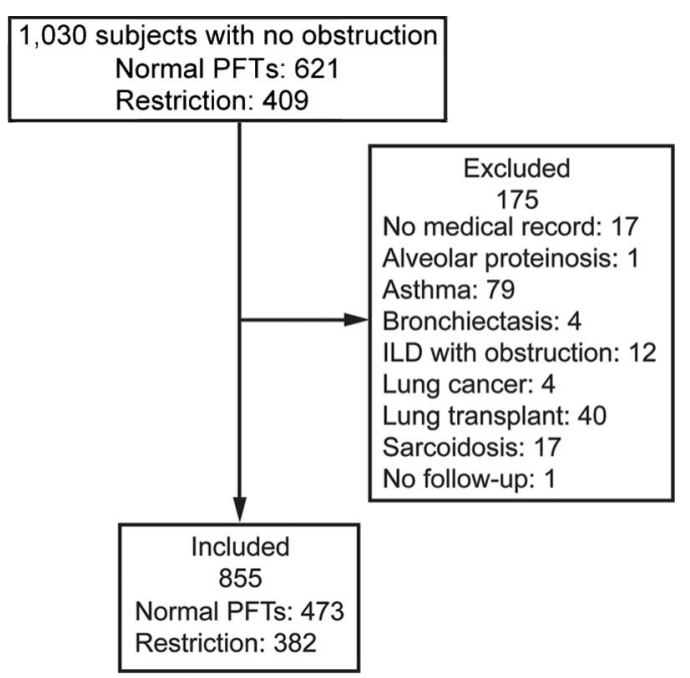

Fig. 2. Flow chart. PFTs = pulmonary function tests, ILD = interstitial lung disease.

ment. Table 1 shows the characteristics, comorbidities, and treatment of individuals included in the analysis. Approximately $19 \%$ of the subjects were seen by a pulmonologist. In subjects $>50$ y old, the prevalence of empiric COPD diagnosis was 8.8\%. In 28 cases, the pulmonologist discontinued treatment, but the primary care physician continued treatment with bronchodilators and/or inhaled glucocorticoids.

In the total sample, persistent empiric COPD diagnosis was associated with older age (odds ratio $[\mathrm{OR}]=1.03 / \mathrm{y}$, $P=.005)$ and current $(\mathrm{OR}=44.7, P<.001)$ and former smoking $(\mathrm{OR}=17.3, P<.001)$ (Table 2$)$.

In never-smokers and current smokers, none of the variables were associated with persistent empiric COPD diagnosis. In former smokers, age was associated with persistent empiric COPD diagnosis $(\mathrm{OR}=1.03$, $95 \% \mathrm{CI}=1.01-1.06, P=.007)$.

Table 3 shows persistent empiric treatment stratified by health-care provider respiratory diagnosis and the presence of a restrictive ventilatory defect in the PFT. In the total sample, female sex $(\mathrm{OR}=1.75, P=.002)$, current $(\mathrm{OR}=2.04, P=.040)$ and former smoking $(\mathrm{OR}=1.53$, $P=.03)$, empiric COPD diagnosis $(\mathrm{OR}=24.6, P<.001)$, interstitial lung disease $(\mathrm{OR}=2.09, P=.001)$, other respiratory diagnosis $(\mathrm{OR}=3.17, P<.001)$, and OSA $(\mathrm{OR}=1.79, P=.006)$ were associated with persistent empiric treatment (see Table 4).

In the subgroup of subjects with persistent empiric COPD diagnosis, only hypertension was associated with persistent empiric treatment $(\mathrm{OR}=4.15,95 \% \mathrm{CI}=1.06-16.2$, $P=.41)$. In subjects with interstitial lung disease, female 
Table 1. Characteristics, Comorbidities, and Treatment of Individuals With Normal Pulmonary Function Test or a Restrictive Ventilatory Defect

\begin{tabular}{|c|c|c|c|c|c|}
\hline $\begin{array}{c}\text { Health-Care Provider } \\
\text { Diagnosis }\end{array}$ & $\begin{array}{c}\text { All } \\
(N=855)\end{array}$ & $\begin{array}{l}\text { COPD } \\
(n=60)\end{array}$ & $\begin{array}{c}\text { ILD } \\
(n=168)\end{array}$ & $\begin{array}{c}\text { Other } \\
(n=147)\end{array}$ & $\begin{array}{c}\text { None } \\
(n=480)\end{array}$ \\
\hline Age, mean \pm SD y & $58.3 \pm 16.5$ & $66.2 \pm 12.1$ & $63.8 \pm 12.2$ & $60.4 \pm 16.2$ & $54.7 \pm 17.4$ \\
\hline Female, $n(\%)$ & $359(42)$ & $25(41.7)$ & $90(53.6)$ & $65(44.2)$ & $179(37.3)$ \\
\hline $\mathrm{BMI}$, mean $\pm \mathrm{SD} \mathrm{kg} / \mathrm{m}^{2}$ & $29.9 \pm 6.7$ & $30.9 \pm 7.7$ & $29.7 \pm 5.9$ & $30.8 \pm 7.2$ & $29.5 \pm 6.6$ \\
\hline Height, mean $\pm \mathrm{SD} \mathrm{cm}$ & $170.8 \pm 10.3$ & $170.9 \pm 9.4$ & $169.5 \pm 9.9$ & $169.9 \pm 10.9$ & $171.6 \pm 10.3$ \\
\hline \multicolumn{6}{|l|}{ Smoking, $n(\%)$} \\
\hline Current & $65(7.6)$ & $10(16.7)$ & $3(1.8)$ & $10(6.8)$ & $42(8.8)$ \\
\hline Former & $440(51.5)$ & $48(80)$ & $101(60.1)$ & $72(49)$ & $219(45.6)$ \\
\hline Never & $350(40.9)$ & $2(3.3)$ & $64(38.1)$ & $65(44.2)$ & $219(45.6)$ \\
\hline $\mathrm{RVD}, n(\%)$ & $382(44.7)$ & $35(58.3)$ & $131(78)$ & $54(36.7)$ & $162(33.8)$ \\
\hline \multicolumn{6}{|l|}{ Comorbidities, $n(\%)$} \\
\hline CAD & $180(21.1)$ & $24(40)$ & $29(17.3)$ & $34(23.1)$ & $93(19.4)$ \\
\hline $\mathrm{CHF}$ & $157(18.4)$ & $18(30)$ & $20(11.9)$ & $37(25.2)$ & $82(17.1)$ \\
\hline CKD & $149(17.4)$ & $12(20)$ & $12(7.1)$ & $31(21.1)$ & $94(19.6)$ \\
\hline DM & $178(20.8)$ & $14(23.3)$ & $28(16.7)$ & $34(23.1)$ & $102(21.3)$ \\
\hline HTN & $486(56.8)$ & $43(71.7)$ & $92(54.7)$ & $90(61.2)$ & $261(54.4)$ \\
\hline OSA & $163(19.1)$ & $13(21.7)$ & $30(17.9)$ & $34(23.1)$ & $86(17.9)$ \\
\hline \multicolumn{6}{|l|}{ Medications, $n(\%)$} \\
\hline SABA & $192(22.5)$ & $45(75)$ & $42(25)$ & $46(31.3)$ & $59(12.3)$ \\
\hline Inhaled steroids & $81(9.5)$ & $27(45)$ & $17(10.1)$ & $18(12.2)$ & $19(4)$ \\
\hline LABA & $63(7.4)$ & $23(38.3)$ & $14(8.3)$ & $13(8.8)$ & $13(2.7)$ \\
\hline Anticholinergics & $43(5)$ & $22(36.7)$ & $8(4.8)$ & $6(4.1)$ & $7(1.5)$ \\
\hline $\begin{array}{l}\mathrm{LD}=\text { interstitial lung } \text { disease } \\
\mathrm{BMI}=\text { body mass index } \\
\mathrm{RVD}=\text { restrictive ventilatory de } \\
\mathrm{CAD}=\text { coronary artery disease } \\
\mathrm{CHF}=\text { congestive heart failure } \\
\mathrm{CKD}=\text { chronic kidney disease } \\
\mathrm{DM}=\text { diabetes mellitus } \\
\mathrm{HTN}=\text { hypertension } \\
\mathrm{OSA}=\text { obstructive sleep apnea } \\
\mathrm{SABA}=\text { short-acting } \beta \text { agonist } \\
\mathrm{LABA}=\text { long-acting } \beta \text { agonist }\end{array}$ & & & & & \\
\hline
\end{tabular}

sex $(\mathrm{OR}=2.57,95 \% \mathrm{CI}=1.21-5.47, P=.01)$ and higher body mass index (OR $=1.09 /$ unit, $95 \% \mathrm{CI}=1.03-$ $1.16, P=.005)$ were associated with treatment with bronchodilators and/or inhaled glucocorticoids. In subjects with other respiratory diagnosis and subjects with no respiratory diagnosis, none of the variables were associated with empiric treatment.

\section{Discussion}

Our study reveals that $25.6 \%$ of subjects with normal $\mathrm{FEV}_{1} / \mathrm{FVC}$ have nonspecific PFT abnormalities. Seven percent of subjects persistently carried an empiric COPD diagnosis 1.5-2 y after the PFT showed no obstruction. Older age and smoking were associated with persistent empiric COPD diagnosis. Twenty-four percent of all subjects, $82 \%$ of individuals with persistent empiric COPD diagnosis, $26 \%$ of subjects with interstitial lung disease, and $34 \%$ of subjects with other respiratory diagnoses received persistent empiric treatment with bronchodilators and/or inhaled glucocorticoids. Persistent empiric treatment was associated with female sex, smoking, empiric COPD diagnosis, interstitial lung disease, other respiratory diagnosis, and OSA.

$\mathrm{FEV}_{1} / \mathrm{FVC}<$ lower limit of normal is often considered diagnostic of COPD. In several studies that examined empiric $\mathrm{COPD}$ diagnosis and treatment, $\mathrm{FEV}_{1} / \mathrm{FVC} \geq$ lower limit of normal was used to exclude COPD diagnosis. ${ }^{2,3,15}$ However, as other investigators have shown previously, 7,16 we found that $25.6 \%$ (234 of 1,384) of PFTs with $\mathrm{FEV}_{1} / \mathrm{FVC} \geq$ lower limit of normal and 13\% (234 of 1,805) of all PFTs had nonspecific PFT patterns. Although these patterns do not necessarily represent obstructive lung disease, we did not include these subjects in the analysis because some of these PFTs may occur in patients with obstruction, ${ }^{12}$ and they are also considered obstructive according to ATSERS guidelines. ${ }^{6}$ Eighty-eight of those subjects had normal spirometry, but they had air trapping and/or hyperinflation. Air trapping and hyperinflation are associated with dyspnea, exercise limitation, accelerated lung function decline, and mortality. ${ }^{17-20}$ 
Table 2. Multivariable Logistic Regression for Factors Associated With Persistent Empiric COPD Diagnosis by Health-Care Provider (Overdiagnosis, $n=60$ ) After Finding a Normal Pulmonary Function Test or a Restrictive Ventilatory Defect $(n=855)$

\begin{tabular}{|c|c|c|c|c|c|c|}
\hline & \multicolumn{3}{|c|}{ Unadjusted } & \multicolumn{3}{|c|}{ Multivariable Adjusted } \\
\hline & OR & $95 \% \mathrm{CI}$ & $P$ & OR & $95 \% \mathrm{CI}$ & $P$ \\
\hline Age (per year) & 1.04 & $1.02-1.06$ & $<.001$ & 1.03 & $1.01-1.06$ & .005 \\
\hline Female & 0.99 & $0.58-1.68$ & .96 & & & \\
\hline BMI (per $1 \mathrm{~kg} / \mathrm{m}^{2}$ ) & 1.02 & $0.99-1.06$ & .2 & & & \\
\hline Height (per cm) & 1 & $0.98-1.03$ & .98 & & & \\
\hline \multicolumn{7}{|l|}{ Smoking } \\
\hline Current & 31.6 & $6.75-148$ & $<.001$ & 44.7 & $9.3-215$ & $<.001$ \\
\hline Former & 21.3 & $5.14-88.3$ & $<.001$ & 17.3 & $4.2-72.1$ & $<.001$ \\
\hline \multicolumn{7}{|l|}{ Never } \\
\hline RVD in PFT & 1.81 & $1.06-3.08$ & 0.029 & & & \\
\hline \multicolumn{7}{|l|}{ Comorbidities } \\
\hline CAD & 2.73 & $1.58-4.71$ & $<.001$ & 1.73 & $0.93-3.19$ & .08 \\
\hline $\mathrm{CHF}$ & 2.02 & $1.13-3.62$ & .02 & & & \\
\hline CKD & 1.2 & $0.62-2.32$ & .59 & & & \\
\hline DM & 1.17 & $0.63-2.18$ & .62 & & & \\
\hline HTN & 2.01 & $1.13-3.58$ & .02 & & & \\
\hline OSA & 1.19 & $0.63-2.25$ & .6 & & & \\
\hline \multicolumn{7}{|l|}{$\mathrm{OR}=$ odds ratio } \\
\hline \multicolumn{7}{|l|}{$\mathrm{BMI}=$ body mass index } \\
\hline \multicolumn{7}{|c|}{ RVD in PFT = restrictive ventilatory defect in pulmonary function test } \\
\hline \multicolumn{7}{|c|}{$\mathrm{CAD}=$ coronary artery disease } \\
\hline \multicolumn{7}{|c|}{$\mathrm{CHF}=$ heart failure } \\
\hline \multirow{2}{*}{\multicolumn{7}{|c|}{$\begin{array}{l}\mathrm{CKD}=\text { chronic kidney disease } \\
\mathrm{DM}=\text { diabetes mellitus }\end{array}$}} \\
\hline \multicolumn{5}{|l|}{$\mathrm{DM}=$ diabetes mellitus } & & \\
\hline \multirow{2}{*}{\multicolumn{7}{|c|}{ HTN $=$ hypertension }} \\
\hline OSA $=$ obstructive sleep a & apnea & & & & & \\
\hline
\end{tabular}

The prevalence of persistent empiric COPD diagnosis was $7 \%$, which is lower than other reports have described, ${ }^{2,3,5}$ probably because we reviewed physician diagnosis after PFT, whereas previous reports reviewed that before. ${ }^{2}$ We also did not include patients whose PFTs could potentially be part of the obstructive spectrum, and our study was conducted in a different population.

Persistent empiric COPD diagnosis is associated with older age. Other investigators have shown that older subjects who carry an empiric COPD diagnosis are more likely to have $\mathrm{FEV}_{1} / \mathrm{FVC} \geq$ lower limit of normal. ${ }^{1,2}$ This "discrepancy" probably results from the different study design. We examined whether subjects with non-obstructive PFTs were overdiagnosed, whereas other reports examined whether subjects who carried a COPD diagnosis had obstruction. ${ }^{2}$ For the same reason, we found that smoking is associated with an increased risk for persistent empiric COPD diagnosis among all subjects with non-obstructive PFTs, whereas other investigators observed that individuals who carry an empiric COPD diagnosis are more likely to have $\mathrm{FEV}_{1} / \mathrm{FVC}<$ lower limit of normal if they are smokers. ${ }^{2}$
We did not observe any association of higher body mass index and persistent empiric diagnosis of COPD, although body mass index has been reported to be a risk factor for overdiagnosis. ${ }^{2}$ Our results suggest an association with coronary artery disease and empiric COPD $(P=.08)$. Cardiac comorbidities are often associated with COPD overdiagnosis, probably because individuals with either disease can experience dyspnea. ${ }^{2}$

Overtreatment is often perceived as an identical problem with overdiagnosis because they share common risk factors. However, physicians often prescribe bronchodilators and inhaled glucocorticoids even for conditions and diseases for which they are not indicated because bronchodilators are relatively safe and might be palliative for the patient. To increase the strength of our findings, we excluded subjects with diseases that could justify empiric treatment despite a non-obstructive PFT, like asthma, bronchiectasis, or other obstructive airway diseases. In our sample, $13.5 \%$ of subjects who did not carry any respiratory diagnosis received empiric treatment.

Physicians often prescribe empiric treatment while awaiting confirmation by PFTs. For that reason, we reviewed the electronic medical records $1.5-2 \mathrm{y}$ after the non-obstructive PFTs. Twenty-four percent of all subjects and $82 \%$ of those with persistent empiric COPD diagnosis continued to use medications like bronchodilators and/or inhaled glucocorticoids. Persistent empiric treatment was relatively common even among subjects with interstitial lung disease $(26 \%)$ and those with no respiratory diagnosis $(13 \%)$. The presence of a restrictive ventilatory defect in PFTs did not seem to play any role.

The strongest predictor of persistent empiric treatment was empiric COPD diagnosis. OSA and interstitial lung disease are also associated with empiric treatment in our sample. Although patients with asthma or COPD frequently suffer from OSA, ${ }^{21,22}$ OSA is not a well known independent risk factor for empiric treatment with inhalers. Female sex was also associated with persistent empiric treatment, probably because women more often report dyspnea. ${ }^{23}$ Interestingly, body mass index, which has been described as a risk factor for COPD overtreatment, ${ }^{2}$ was associated with persistent empiric treatment only in subjects with interstitial lung disease and not in our total sample.

Although persistent empiric treatment may represent a sort of therapeutic inertia, ${ }^{24}$ it may also represent the last option to treat unexplained respiratory symptoms, and we should not consider it equivalent to medical error. Although bronchodilators ${ }^{25}$ and inhaled glucocorticoids $^{26}$ are relatively safe, adverse events may occur as they are widely used. Potential harm aside, overtreatment results in increased unnecessary cost of health care. A combination of inhaled glucocorticoids with long-acting $\beta$ agonist costs about $\$ 308$ to $\$ 412$, whereas 


\section{EMPIRIC COPD DiAgnosis AND TREATMENT}

Table 3. Persistent empiric treatment with bronchodilators and/or inhaled glucocorticoids stratified by respiratory diagnosis according to health care provider among individuals who have a normal pulmonary function test or a restrictive ventilatory defect.

\begin{tabular}{|c|c|c|c|c|c|}
\hline & All & COPD & ILD & Other & None \\
\hline Normal PFT & $22 \%(104 / 473)$ & $72 \%(18 / 25)$ & $27 \%(10 / 37)$ & $34.4 \%(32 / 93)$ & $13.8 \%(44 / 318)$ \\
\hline RVD & $27.2 \%(104 / 382)$ & $88.6 \%(31 / 35)$ & $26 \%(34 / 131)$ & $33.3 \%(18 / 54)$ & $13 \%(21 / 162)$ \\
\hline Total & $24.3 \%(208 / 855)$ & $81.7 \%(49 / 60)$ & $26.2 \%(44 / 168)$ & $34 \%(50 / 147)$ & $13.5 \%(65 / 480)$ \\
\hline
\end{tabular}

Note: each cell contains $\%$ empirically treated ( $\mathrm{n}$ empirically treated $/ \mathrm{n}$ at risk) COPD $=$ chronic obstructive pulmonary disease, ILD $=$ interstitial lung disease, $\mathrm{PFT}=$ pulmonary function test, and $\mathrm{RVD}=$ restrictive ventilatory defect.

Table 4. Multivariable Logistic Regression Analysis of Factors Associated With Persistent Empiric Treatment With Bronchodilators and/or Inhaled Glucocorticoids $(n=208)$ in 855 Individuals With a Normal Pulmonary Function or a Restrictive Ventilatory Defect

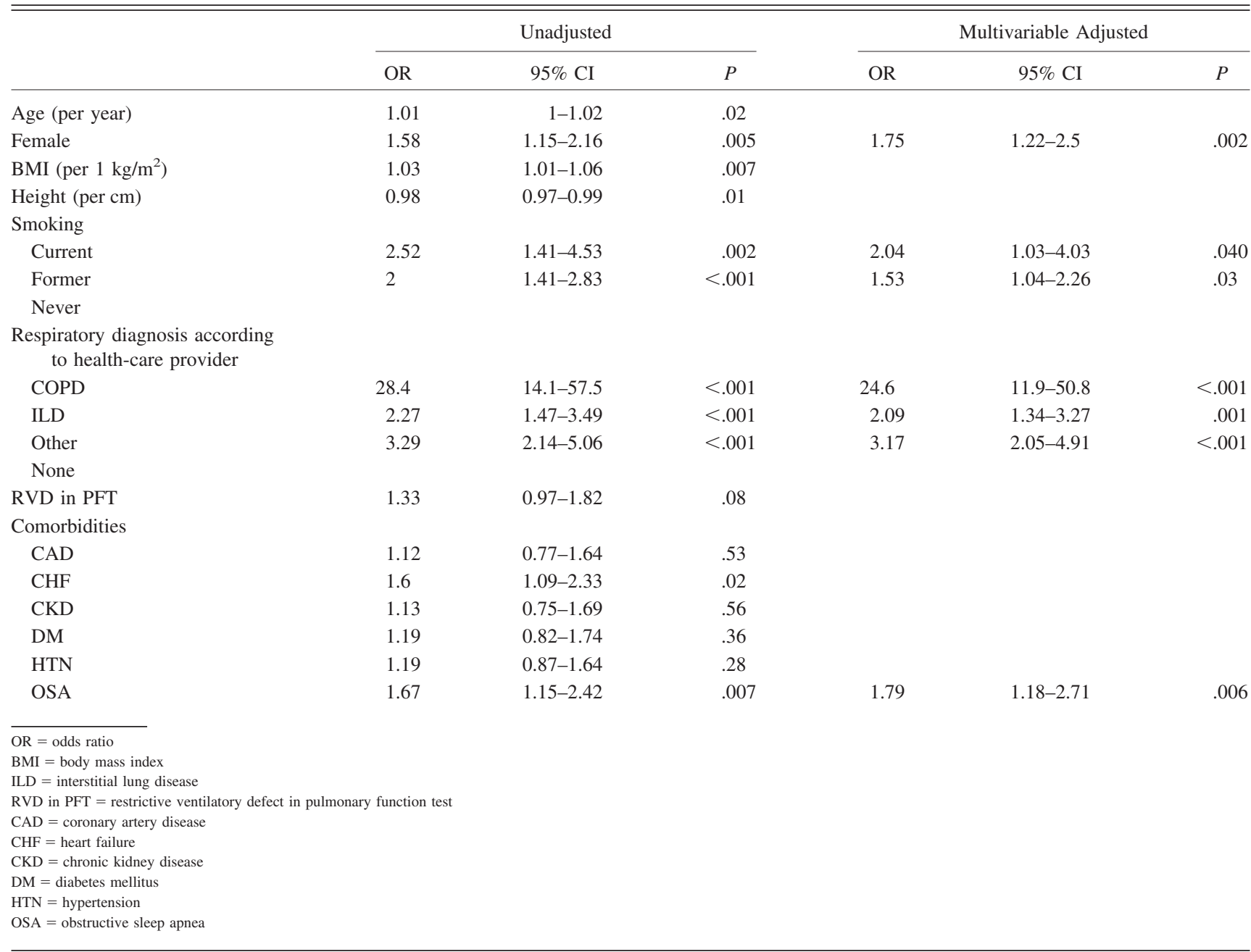

anticholinergic inhalers cost from $\$ 340$ to $\$ 411 /$ month based on online price lists of United States pharmacies. Of 1,805 subjects in our cohort, 81 used unnecessary inhaled steroids with long-acting $\beta$ agonist, and 43 received anticholinergic inhalers inappropriately. This correlates with as much as $\$ 45,000$ unnecessary cost/month, or $\$ 540,000 / y$, only from inhaled steroids, long-acting $\beta$ agonists, and anticholinergics. In other words, for every individual who had a PFT in our laboratory, there was about $\$ 300$ of possibly unnecessary annual expenses. Considering that only a third of patients who are labeled with a COPD diagnosis have PFTs ${ }^{4}$ and that the majority of those with a COPD diagnosis and who do have PFTs have only spirometric testing, unnecessary cost due to overtreatment may be much larger than is estimated here. 
Apart from its retrospective nature, our study has several other limitations. We included even young adults, although COPD is more prevalent among older individuals. However, the prevalence of COPD among subjects $>50$ y old was $8.8 \%$, similar to the $7 \%$ in our whole cohort. We did not follow serial PFTs, so we do not know whether abnormal PFTs had normalized after treatment. We did not include patients with nonspecific PFT abnormalities because it is unknown whether those patients have obstructive lung diseases like COPD. We cannot ensure that the health-care providers actually reviewed the PFT results, although our electronic medical record sends the results electronically to the provider who orders the PFT and requires that the results eventually be opened (but we cannot guarantee that they are ever read). To minimize that risk, we reviewed the electronic medical records of subjects with empiric COPD diagnosis and treatment for several months after the PFTs. In this report, we did not consider lung imaging or other clinical data like symptoms of chronic bronchitis that can support the COPD diagnosis or treatment despite a $\mathrm{FEV}_{1} / \mathrm{FVC} \geq$ lower limit of normal. Some patients may have had radiographic air trapping or emphysema with normal PFTs. ${ }^{27}$ Because this study was conducted in only one health-care system, these results should be generalized cautiously. Despite the above limitations, the existence of a non-negligible amount of overdiagnosis and overtreatment is probably real and should be further investigated in more precise study designs.

\section{Conclusions}

One quarter of the subjects with normal $\mathrm{FEV}_{1} / \mathrm{FVC}$ had nonspecific PFT abnormalities. Seven percent of the subjects continued to carry an empiric COPD diagnosis after PFT showed no obstruction. Persistent empiric COPD diagnosis was more common among the elderly and smokers. Persistent empiric treatment occurred in $82 \%$ of individuals who carried an empiric COPD diagnosis, $26 \%$ of subjects with interstitial lung disease, and $34 \%$ of subjects with other respiratory diagnoses. Persistent empiric treatment with bronchodilators and inhaled glucocorticoids was associated with female sex, smoking, empiric COPD diagnosis, interstitial lung disease, other respiratory diagnosis, and OSA. Health-care providers should avoid inappropriate treatment with bronchodilators and inhaled glucocorticoids that increases medical cost and potentially results in unnecessary adverse effects.

\section{REFERENCES}

1. Lee TA, Bartle B, Weiss KB. Spirometry use in clinical practice following diagnosis of COPD. Chest 2006;129(6):1509-1515.
2. Collins BF, Feemster LC, Rinne ST, Au DH. Factors predictive of airflow obstruction among veterans with presumed empiric diagnosis and treatment of COPD. Chest 2015;147(2):369-376.

3. Collins BF, Ramenofsky D, Au DH, Ma J, Uman JE, Feemster LC. The association of weight with the detection of airflow obstruction and inhaled treatment among patients with a clinical diagnosis of COPD. Chest 2014;146(6):1513-1520.

4. Han MK, Kim MG, Mardon R, Renner P, Sullivan S, Diette GB, Martinez FJ. Spirometry utilization for COPD: how do we measure up? Chest 2007;132(2):403-409.

5. Fortis S, Kittah J, De Aguirre M, Plataki M, Wolff A, AmoatengAdjepong Y, Manthous CA. Perseverant, non-indicated treatment of obese patients for obstructive lung disease. BMC Pulm Med 2013; 13:68.

6. Pellegrino R, Viegi G, Brusasco V, Crapo RO, Burgos F, Casaburi $\mathrm{R}$, et al. Interpretative strategies for lung function tests. Eur Respir J 2005;26(5):948-968.

7. Hyatt RE, Cowl CT, Bjoraker JA, Scanlon PD. Conditions associated with an abnormal nonspecific pattern of pulmonary function tests. Chest 2009;135(2):419-424.

8. Fortis S, Corazalla EO, Wang Q, Kim HJ. The difference between slow and forced vital capacity increases with increasing body mass index: a paradoxical difference in low and normal body mass indices. Respir Care 2015;60(1):113-118.

9. Miller MR, Crapo R, Hankinson J, Brusasco V, Burgos F, Casaburi $\mathrm{R}$, et al. General considerations for lung function testing. Eur Respir J 2005;26(1):153-161.

10. Miller MR, Hankinson J, Brusasco V, Burgos F, Casaburi R, Coates A, et al. Standardisation of spirometry. Eur Respir J 2005;26(2):319338.

11. Wanger J, Clausen JL, Coates A, Pedersen OF, Brusasco V, Burgos F, et al. Standardisation of the measurement of lung volumes. Eur Respir J 2005;26(3):511-522.

12. Iyer VN, Schroeder DR, Parker KO, Hyatt RE, Scanlon PD. The nonspecific pulmonary function test: longitudinal follow-up and outcomes. Chest 2011;139(4):878-886.

13. Hankinson JL, Odencrantz JR, Fedan KB. Spirometric reference values from a sample of the general U.S. population. Am J Respir Crit Care Med 1999;159(1):179-187.

14. Quanjer PH, Tammeling GJ, Cotes JE, Pedersen OF, Peslin R, Yernault JC. Lung volumes and forced ventilatory flows. Report Working Party Standardization of Lung Function Tests, European Community for Steel and Coal. Official Statement of the European Respiratory Society. Eur Respir J Suppl 1993;16:5-40.

15. García-Rio F, Soriano JB, Miravitlles M, Muñoz L, Duran-Tauleria E, Sánchez G, et al. Overdiagnosing subjects with COPD using the 0.7 fixed ratio: correlation with a poor health-related quality of life. Chest 2011;139(5):1072-1080.

16. Wan ES, Hokanson JE, Murphy JR, Regan EA, Make BJ, Lynch DA, et al. Clinical and radiographic predictors of GOLD-unclassified smokers in the COPDGene study. Am J Respir Crit Care Med 2011;184(1):57-63

17. Casanova C, Cote C, de Torres JP, Aguirre-Jaime A, Marin JM, Pinto-Plata V, Celli BR. Inspiratory-to-total lung capacity ratio predicts mortality in patients with chronic obstructive pulmonary disease. Am J Respir Crit Care Med 2005;171(6):591-597.

18. Cooper CB. The connection between chronic obstructive pulmonary disease symptoms and hyperinflation and its impact on exercise and function. Am J Med 2006;119(10 Suppl 1):21-31.

19. O'Donnell DE. Hyperinflation, dyspnea, and exercise intolerance in chronic obstructive pulmonary disease. Proc Am Thorac Soc 2006; 3(2): 180-184.

20. Mets OM, de Jong PA, van Ginneken B, Kruitwagen CL, Prokop M, 


\section{EMPIRIC COPD DiAgnosis AND TREATMENT}

Oudkerk M, et al. CT air trapping is independently associated with lung function reduction over time. PLoS One 2013;8(4):e61783.

21. Teodorescu M, Barnet JH, Hagen EW, Palta M, Young TB, Peppard PE. Association between asthma and risk of developing obstructive sleep apnea. JAMA 2015;313(2):156-164

22. Zamarrón C, García Paz V, Morete E, del Campo Matías F. Association of chronic obstructive pulmonary disease and obstructive sleep apnea consequences. Int J Chron Obstruct Pulmon Dis 2008; 3(4):671-682.

23. Camp PG, Goring SM. Gender and the diagnosis, management, and surveillance of chronic obstructive pulmonary disease. Proc Am Thorac Soc 2007;4(8):686-691.

24. Lebeau JP, Cadwallader JS, Aubin-Auger I, Mercier A, Pasquet T, Rusch E, et al. The concept and definition of therapeutic inertia in hypertension in primary care: a qualitative systematic review. BMC Fam Pract 2014;15:130.

25. Tashkin DP, Leimer I, Metzdorf N, Decramer M. Cardiac safety of tiotropium in patients with cardiac events: a retrospective analysis of the UPLIFT trial. Respir Res 2015;2(16)65. doi: 10.1186/s12931015-0216-4.

26. Calverley PM, Anderson JA, Celli B, Ferguson GT, Jenkins C, Jones $\mathrm{PW}$, et al. Salmeterol and fluticasone propionate and survival in chronic obstructive pulmonary disease. N Engl J Med 2007;356(8): 775-789.

27. Lutchmedial SM, Creed WG, Moore AJ, Walsh RR, Gentchos GE, Kaminsky DA. How common is airflow limitation in patients with emphysema on computerized tomography of the chest? Chest 2015; 148(1):176-184. 